\title{
MARTORELL CAMPOS, FRANCISCO (2019). SOÑAR DE OTRO MODO: CÓMO PERDIMOS LA UTOPÍA Y DE QUÉ FORMA RECUPERARLA, 2019. LA CAJA BOOKS. ISBN 978-84-17496-22-7.155 P.
}

\author{
Lucas Misseri \\ (Universidad de Alicante, Argentina) \\ lucmisseri@gmail.com
}

Recibido: 07/06/2019

Aprobado: 15/07/2019

Francisco Martorell Campos nació en Valencia en 1971 y se doctoró en Filosofía por la universidad de esa misma ciudad, con una tesis sobre teoría de la utopía. Dicho trabajo es hoy una de las referencias más actualizadas de los estudios de la utopía en castellano. Esa tesis, Transformaciones de la utopía y la distopía en la postmodernidad, obtuvo el premio extraordinario de doctorado en 2017 y es una de las fuentes del texto que aquí se reseña. Otras fuentes son los trabajos realizados por Martorell en torno a las distintas aristas del utopismo contemporáneo tanto en artículos de revistas académicas como en intercambios con el resto de los miembros del grupo de estudios Histopía de la Universidad Autónoma de Madrid, que dirige Juan Pro Ruiz.

En esta ocasión, Martorell deja a un lado la prosa académica para ofrecer un texto de "tono ensayístico-panfletario", que huelga decir, es el tono de muchas utopías. Esto porque a nuestro autor le sientan bien los dos sentidos del término "estudioso utópico". Por un lado, es un erudito del utopismo occidental y, por el otro, es un pensador utópico en el sentido de que su pensamiento tiene una fuerte pulsión utópica. Con esto último quiero decir que el filósofo valenciano cree que las utopías, sobre todo las "utopías sociales", tienen que recuperar su rol emancipador y activo en nuestras sociedades, convicción que procura justificar y difundir en Soñar de otro modo.

Ahora bien, ¿a qué nos referimos cuando hablamos de utopía? La bibliografía sobre el tema es copiosa y en muchas ocasiones contradictoria. Nuestro autor, tras haber abrevado en una diversidad de fuentes que van desde Ernst Bloch a Tower Lyman Sargent pasando por Fredric Jameson, toma partido por considerar que en el concepto de utopía sobresalen tres elementos: 1) el deseo utópico, 2) la forma utópica, y 3) la política utópica. Si bien los tres están entremezclados, el foco de Martorell está puesto en el segundo elemento, el textual, dentro del cual distingue, a la "literatura utópica social", que nace con Utopía de Moro (1516), y a la "literatura tecnoutópica", que nace con la Nueva Atlántida de Francis Bacon (1627). Ambas tradiciones convergerán con frecuencia durante la modernidad. Otra afirmación interesante de Martorell está en considerar a la distopía no como antiutopía estricta, esto es como rechazo unilateral del utopismo, sino como una crítica de utopías concretas que incluye veladamente una utopía.

Hechas estas precisiones, puede avanzarse que la tesis central de Soñar de otro modo es que hay algo que puede ser denominado la "utopía paradigmática de la modernidad", con su contrapartida distópica. Esta utopía estándar ha sido desplazada por las transformaciones acaecidas durante la posmodernidad en todos los ámbitos, eventos que para Martorell han vuelto obsoletos los supuestos del utopismo tradicional en la teoría y la práctica. Pero, lo interesante (y utópico) del planteo del valenciano es que dicha obsolescencia no entraña la caducidad del utopismo en sí, sino de las utopías asociadas a los planteos metafísicos de la Modernidad. Una de las tesis más fuertes sostenidas en el libro es que la utopía precisa someterse a una segunda secularización anticipada por algunas de las dinámicas progresistas de la posmodernidad. Para Martorell la utopía precisa volverse postfundacionalista y antiautoritaria, desligarse de la metafísica moderna que tantos siglos la ha acompañado y que propició sus orientaciones totalitarias. La primera secularización, cristalizada en el iluminismo, dejó de lado la idea 
de Dios, pero el espacio dejado por la divinidad fue rápidamente reemplazado por las ideas de Naturaleza e Historia, entendidas como fuerzas deterministas que actúan al margen de la voluntad humana e imponen deberes, fundamentos y sentidos a los seres humanos.

Martorell remite esta segunda secularización a los planteos de Gianni Vattimo y Jacques Derrida, pero quien más influye en su visión es el estadounidense Richard Rorty. Esto porque, si bien se acepta el carácter destructivo de la visión posmodernista de los primeros, concuerda con el segundo en que la secularización virtualmente abierta por la posmodernidad beneficia al ideario humanista y a los valores y contenidos estrictamente políticos de la Ilustración. Para él la política ilustrada puede y debe ser separada de la metafísica ilustrada. La utopía secularizada en este sentido es abierta, cambiante, pluralista y falible; algo que ya había avizorado H. G. Wells sin poderlo materializar en su Utopía Moderna de 1905. Pero al mismo tiempo esa utopía resecularizada debe respetar todavía el proyecto de universalizar la libertad, la igualdad y la fraternidad. Martorell sugiere que el nuevo camino para la utopía se abre al rechazar los excesos del esencialismo moderno y los del particularismo posmoderno.

Soñar de otro modo está dividido en tres actos, otro guiño al tono distendido del texto. El primero se titula "La naturaleza", el segundo "La historia" y el tercero "La sociedad". Tres grandes ámbitos cuestionados por la idea de una segunda secularización, a partir de los cuales Martorell, siguiendo algunas ideas de F. Jameson, S. Žižek, J.Baudrillard, Félix Duque, Z. Bauman, Manuel Cruz, J.-F. Lyotard y Byung-Chul Han, entre otros, realiza cuatro cosas: un análisis de la utopía moderna ligado a los ámbitos señalados, un análisis de cómo la posmodernidad los elimina, una crítica de la ideología neoliberal desplegada alrededor de dicha eliminación y una propuesta para repensar, renovar e impulsar la utopía en nuestros días a partir de una lectura izquierdista de la caída de la naturaleza, la historia y la sociedad.

Para describir la semiosis del término "naturaleza" se vale de la clasificación de Erik Swyngedouw, según la cual este término puede referir a una naturaleza física, creadora, esencial o normativa. La naturaleza tiene un papel básico en las utopías modernas, bien porque encarna el material preexistente a dominar mediante la tecnología, bien porque inspira el regreso a un espacio inmaculado. Pero insiste Martorell en que la idea de naturaleza es insostenible desde la posmodernidad, así como las narraciones utópicas asociadas a ella. De hecho, algunas utopías empiezan a dar cuenta de la desnaturalización, tal es el caso del transhumanismo y la obras como la Trilogía Marciana del estadounidense Kim Stanley Robinson. Esta última es para el valenciano el mejor ejemplo de utopía secularizada que existe hasta ahora.

Para Martorell, el fin de la naturaleza es inseparable del fin de la historia, proceso que desemboca en la deshistorización plasmada en el conmemoracionismo, en la abundancia de remakes, impulsos nostálgicos, rituales de la memoria y mercancías vintage que caracterizan a la cultura actual. La historia deviene un conjunto de anécdotas que más que narrar el pasado lo trocean y reinventan. Mientras tanto, el futuro desaparece como horizonte colectivo de emancipación, y todo, incluidas las políticas reivindicativas, se pliega al puro presente, al corto plazo, al leitmotiv thatcheriano de que "no hay alternativa". El escenario derivado de todo esto es muy hostil para el utopismo. El autor señala que para empezar a revertirlo necesitamos de unas nociones no metafísicas de futuro y progreso, ajenas a la filosofía moderna de la historia, que sirvan de vehículos para la esperanza secularizada, en un mundo distinto y mejor. Los fragmentos existentes al respecto en la trilogía de Robinson ofrecen algunas pistas a tener en cuenta.

Por último, Martorell inspecciona la desocialización surgida de la fragmentación social. Para él, su primer síntoma es el diferencialismo, es decir, la celebración colectiva, también interiorizada por las políticas reivindicativas recientes, de la diferencia y la particularidad, gesto unido a la condena unánime de la igualdad y la universalidad, nociones que Martorell también considera preciso recuperar en formato secularizado. El diferencialismo y la consiguiente exigencia de ser diferentes actúan junto al privatismo, tendencia en la que lo público es conquistado por lo privado, causando una especie de voyeurismo social en la que prima la obligación de ser transparentes. El tercer síntoma de la 
desocialización se expresa en la exigencia de ser autosuficientes, proclama desarrollada junto a la reconfiguración neoliberal de los Estados que condena a los más débiles al desamparo y la incertidumbre. Basándose de nuevo en fragmentos de la Trilogía marciana de Robinson, Martorell muestra la conveniencia de intentar conjugar diferencia e igualdad, privacidad y transparencia, autosuficiencia y seguridad.

El llamamiento a "soñar de otro modo" de Martorell se justifica porque, como bien afirma, el "mundo no mejora por sí solo". Las claves para pensar la mejora del mundo surgen del balance entre el proyecto político ilustrado y la crítica posmoderna a la metafísica, en pensar a la naturaleza desde su artificialidad, a la historia desde su contingencia y a la sociedad desde su carácter de red sin un centro específico. La propuesta de Martorell en su conjunto tiene un gran valor, en tanto que intento de realizar una crítica de la utopía desde dentro de la misma tradición utópica. Esa crítica se extiende de la utopía moderna (metafísica, afectada casi siempre por hábitos totalitarios) a la posmoderna (convertida en una especie de microutopismo al servicio del culto a la diferencia identitaria), del neoliberalismo hegemónico al izquierdismo cultural, pasando por el distopismo que impera en el imaginario colectivo desde mediados del siglo pasado. Este último objeto de su crítica es incuestionable, y creo que su llamamiento a revitalizar el impulso eutópico en detrimento del distópico, a potenciar la búsqueda de alternativas constructivas a lo dado en detrimento de los enfoques que simplemente lo desenmascaran e impugnan, es digno de elogio y fomento. No obstante, con respecto al equilibrio entre rasgos modernos y posmodernos de su visión resecularizante de la utopía albergo algunas dudas: ¿cómo sostener los valores de la Ilustración sin algún componente metafísico? ¿Cómo defender la igualdad sin alguna idea de qué es lo que es igual? ¿Cómo defender, por mucho que se haga desde la unidad y la igualdad, la pluralidad y la diferencia sin recaer en el microutopismo? Las respuestas a estas preguntas constituyen parte del desafío del utopismo de nuestro siglo. Si bien sería demasiado pedirle a Martorell que dé respuesta a todos estos interrogantes, podemos decir con certeza que su obra utopológica (este libro en particular, pero sobre todo el conjunto de su obra) contribuye a la construcción de respuestas en base a una hoja de ruta en la que ya sabemos qué realzar y qué descartar. El camino está en repensar el vínculo entre los ideales de justicia social y la utilización de la tecnología como forma de mediatizar nuestras relaciones con los otros, sin anular la individualidad. En resumidas cuentas, creo que la propuesta martorelliana se acerca a algunas ideas que comparto y que englobaría bajo la etiqueta de tecnoprogresismo, pero que precisa aún de mucha discusión y sobre todo de crítica utópica. 